\title{
Twenty-one new sequence markers for population genetics, species delimitation and phylogenetics in wall lizards (Podarcis spp.)
}

\author{
Carolina Pereira', Alvarina Couto ${ }^{1,2}$, Carla Luís ${ }^{1}$, Diogo Costa ${ }^{1,2}$, Sofia Mourão ${ }^{1}$ and Catarina Pinho ${ }^{1 *}$
}

\begin{abstract}
Background: Wall lizards of genus Podarcis are abundant and conspicuous reptiles inhabiting Europe and North Africa. In recent years, they have become a popular lizard model for phylogeographical and evolutionary ecology studies. However a lack of suitable nuclear markers currently presents a limitation on analyses of molecular evolution within this genus. We address this limitation by developing twenty-one new primer pairs for polymerase chain reaction (PCR) amplification and sequencing of anonymous sequence markers in Podarcis vaucheri and performed an assay of their cross-amplification and polymorphism levels in two closely- (P. bocagei and P. liolepis) and two distantly-related (P. muralis and P. tiliguerta) congeners.
\end{abstract}

Findings: Cross-amplification and sequencing was straightforward among members of the Iberian and North-African group within genus Podarcis (which includes $P$. vaucheri), and somewhat less successful in species belonging to other groups (one and four loci out of 21 failed to amplify in $P$. muralis and $P$. tiliguerta, respectively, and overall success rates were lower). Nucleotide diversity for the five species examined ranged from $0.35 \%$ to $3.5 \%$, with an average of $1.5 \%$ across all loci. Insertion and deletion polymorphisms were found in all but three loci.

Conclusions: Given the high cross-amplification rates, these markers constitute a valuable addition to set of genomic resources available for Podarcis, especially in studies dealing with phylogenetics, species delimitation, population genetics and phylogeography.

Keywords: Podarcis, Polymorphism, Lizards, Squamata, Lacertidae, Nuclear sequence marker, Genetic diversity

\section{Findings}

Wall lizards of the genus Podarcis (Squamata: Lacertidae) are among the most conspicuous, abundant and widely distributed reptiles in Europe and North Africa. The genus currently comprises 21 fully recognized (but likely many more) species and exhibits a circum-mediterranean distribution. A recent review [1] indicated that Podarcis, more than any other genus of lizard including Anolis, has been used extensively in studies pertaining to evolutionary ecology and phylogeography.

Nevertheless, there is a striking paucity of genetic markers available for studying the evolution and ecology

\footnotetext{
* Correspondence: catarina@cibio.up.pt

'CIBIO/UP, Centro de Investigação em Biodiversidade e Recursos Genéticos, Universidade do Porto, Campus Agrário de Vairão, Rua Padre Armando Quintas, 4485-661 Vairão, Portugal

Full list of author information is available at the end of the article
}

of this genus. Apart from allozymes, which are impractical for high throughput projects [2], mitochondrial DNA, microsatellite loci, which show extensive levels of homoplasy between species e.g. [3,4] and a few introns $[5,6]$, the genetics tool kit for the genus is very limited, especially in terms of nuclear markers. This is particularly problematic given that the taxonomy of the genus is highly unstable and both inter and intraspecific diversity remain poorly understood. Species such as $P$. erhardii [7], P. hispanica [8] and P. tiliguerta [9] have been suggested to be cryptic species complexes, with non-negligible gene flow among species and pervasive incomplete lineage sorting in nuclear genes [5]. Scenarios of extensive mitochondrial DNA introgression among species have furthermore been reported [10], implying that mtDNA markers alone should not be used for barcoding purposes in this genus. These features imply that a correct assessment of species boundaries and speciation dynamics require more detailed 
genetic studies based on a large battery of different types of genetic markers.

This paper describes primers for 21 nuclear loci in the Moroccan wall lizard Podarcis vaucheri as well as their utility in four other congeners $(P$. bocagei, $P$. liolepis, $P$. muralis and $P$. tiliguerta). $P$. vaucheri is one of the most widespread and genetically structured species within the clade $[8,11]$. It is also the only species in the genus found on both sides of the Strait of Gibraltar, a feature that makes this species a valuable biogeographic model.

Total genomic DNA from a single individual of P. vaucheri (Bab Taza, Chefchaouen province, Morocco) was digested with TasI (Fermentas, Vilnius, Lithuania) according to the manufacturer's protocol.

The digested genomic DNA was subsequently ligated to TSPADSHORT and TSPADLONG adapters [12]. In order to do so, TSPADSHORT and TSPADLONG were previously ligated to each other to obtain a doublestrand adapter by adding $89.2 \mu \mathrm{L}$ of Tris-EDTA buffer, $0.8 \mu \mathrm{L}$ of $\mathrm{NaCl} 5 \mathrm{M}$, and $5 \mu \mathrm{L}$ of each oligonucleotide $(100 \mu \mathrm{M})$. The mixture was placed at $95^{\circ} \mathrm{C}$ for 3 minutes, $65^{\circ} \mathrm{C}$ for 2 minutes, $45^{\circ} \mathrm{C}$ for 2 minutes and $25^{\circ} \mathrm{C}$ for one minute. The double-stranded adapter was then ligated to the digested genomic DNA by adding $50 \mu \mathrm{L}$ of digestion with $10 \mu \mathrm{L}$ of the TSPADSHORT/TSPADLONG adapter, 36 units of T4 DNA ligase (Promega, Fitchburg, Winsconsin, USA) and $28 \mu \mathrm{L}$ of reaction buffer $(300 \mathrm{mM}$ Tris- $\mathrm{HCl}, \mathrm{pH} 7.8,100 \mathrm{mM} \mathrm{MgCl}, 100 \mathrm{mM}$ DTT and $10 \mathrm{mM}$ ATP), followed by an incubation at $16^{\circ} \mathrm{C}$ overnight.

Subsequently, the DNA linked to the double-stranded adapter was used as template for polymerase chain reaction (PCR) using TSPADSHORT as primer. Five replicate $25 \mu \mathrm{L}$ reactions were carried out, each containing 1X PCR buffer $(50 \mathrm{mM}$ Tris- $\mathrm{HCl}, 50 \mathrm{mM} \mathrm{NaCl}$, $\mathrm{pH}$ 8.5); $2 \mathrm{mM} \mathrm{MgCl}_{2} ; 1 \mathrm{mM}$ each dNTP, $2 \mathrm{U}$ of GoTaq DNA polymerase (Promega), $1 \mu \mathrm{M}$ of TSPADSHORT and $1,25 \mu \mathrm{L}$ of the DNA-adapter mixture. Amplification conditions consisted of a step at $72^{\circ} \mathrm{C}$ for 5 minutes, followed by 25 cycles with 1 minute at $94^{\circ} \mathrm{C}, 1$ minute at $55^{\circ} \mathrm{C}$ and 1 minute at $72^{\circ} \mathrm{C}$.

A mixture of the five PCR replicates was then ran on an agarose-TBE gel and fragments of $\sim 400-2000$ bp were gel-isolated using the GE Healthcare Life Sciences (Uppsala, Sweden) Illustra GFX PCR DNA and Gel Band Purification kit. After purification, PCR products were ligated into pGEM-T Easy Vector Systems kit (Promega) according to the manufacturer's instructions. The output of the ligation reaction was then transformed into Escherichia coli competent cells and grown on standard LB medium with ampicillin/IPTG/X-Gal (details on this medium can be found on the pGEM-T Easy Vector Systems protocol); conventional blue/white screening was used to discriminate clones that contained inserts (white) from those that did not (blue).
Using this protocol, a total of 72 positive colonies were obtained. These samples were then amplified using universal primers $\mathrm{pUC} / \mathrm{M} 13 \mathrm{~F}$ and $\mathrm{pUC} / \mathrm{M} 13 \mathrm{R}$. PCR reactions were carried out in $25 \mu \mathrm{L}$ volumes containing $1 \mathrm{X}$ PCR buffer, $\mathrm{MgCl}_{2} ; 1 \mathrm{mM}$ each dNTP, $2 \mathrm{U}$ of GoTaq DNA polymerase (Promega), $0.4 \mu \mathrm{M}$ each primer and $2 \mu \mathrm{L}$ of colony DNA. After verification of successful amplification, the inserts were sequenced from both strands with the same primers used for amplification. Sequencing was performed on an Applied Biosystems 3130xl Genetic Analyzer (Applied Biosystems, Foster City, California).

Sequences were subject to a previous pruning step in order to remove vector sequences. Subsequently, in order to prevent designing primers in repetitive regions, which would lead to difficulties in amplification and/or to the amplification of paralogs, we discarded clones containing putative repetitive elements. In order to identify such clones, we performed a BLAST search [13] against the NCBI (http://www.ncbi.nlm.nih.gov/) nucleotide database and a RepeatMasker [14] run. We also used the standalone version of BLAST to remove putative duplicates and sequences comprising potential repetitive elements not identified by the previous methods. Clones that were excessively small (i.e. with an insert size below $300 \mathrm{bp}$ ) were also discarded.

Thirty-three clone sequences passed this initial quality-control step and were therefore used as template for primer design. These primers were preliminarily tested and optimized by screening across a set of 16 individuals from $P$. vaucheri and other species. Amplifications were carried out in a similar fashion for all loci: in $25 \mu \mathrm{L}$ volumes, containing $1 \mathrm{X}$ PCR buffer; $3 \mathrm{mM} \mathrm{MgCl}_{2}$; $0.6 \mathrm{mM}$ each dNTP, $2 \mathrm{U}$ of GoTaq DNA polymerase (Promega), $0.4 \mu \mathrm{M}$ each primer and approximately $50 \mathrm{ng}$ of genomic DNA. Amplification conditions consisted of a denaturation step at $92^{\circ} \mathrm{C}$ (3 minutes), followed by 40 cycles of denaturation at $92^{\circ} \mathrm{C}$ (30 seconds), an annealing step of 30 seconds and extension at $72^{\circ} \mathrm{C}$ for 1 minute. The first 25 of these cycles were conducted in a touchdown manner, with annealing temperature decreasing $0.5^{\circ} \mathrm{C}$ per cycle from $62^{\circ} \mathrm{C}$ to $50^{\circ} \mathrm{C}$, and in the last 15 cycles the annealing temperature was constant at $50^{\circ} \mathrm{C}$. A final extension was carried out at $72^{\circ} \mathrm{C}$ for $15 \mathrm{mi}-$ nutes. Sequencing was performed in a Applied Biosystems 3130xl Genetic Analyzer.

According to this preliminary screening, 23 primer pairs showed consistent amplification and sequencing success. Two of these presented some evidence for the amplification of paralogs (such as the presence of the same heterozygous positions in all sequences) and were further excluded from the analyses.

Primer sequences for the remaining 21 loci are reported in Table 1. These loci were chosen for a more 
Table 1 Sequences of the primers developed in this study

\begin{tabular}{|c|c|c|}
\hline Locus name & Primer & Sequence $\left(5^{\prime}-3^{\prime}\right)$ \\
\hline \multirow[t]{2}{*}{ Pod6b } & pod6bf & ctggtaatggeccgctatgtatggg \\
\hline & pod6br & ataaagctgggaagctcttgagtcc \\
\hline \multirow[t]{2}{*}{ Pod7b } & pod7bf & gtcactttggtgctgctcgcacagc \\
\hline & pod7br & tgtaatgctgcaacttggcgacacc \\
\hline \multirow[t]{2}{*}{ Pod11 } & pod11f & gactttgggttcaaatctccacccc \\
\hline & pod11r & aggtcatctgcttgactgttctggc \\
\hline \multirow[t]{2}{*}{ Pod12b } & pod12bf & accttcttttgcctacgcacgccag \\
\hline & pod12br & ctgtccacaacacccttattctgcc \\
\hline \multirow[t]{2}{*}{ Pod13 } & $\operatorname{pod} 13 f$ & gcagttgttgctgggctcatttctg \\
\hline & pod13r & acatgattttgaggggacgcaaacc \\
\hline \multirow[t]{2}{*}{ Pod14 } & $\operatorname{pod} 14 f$ & gctttcctatgaggctcaagtttgg \\
\hline & $\operatorname{pod} 14 r$ & agccgactgtctctaataacttccc \\
\hline \multirow[t]{2}{*}{ Pod14b } & pod14bf & ctggaggaagggtagcatgatctcc \\
\hline & pod14br & ctgacagccgcatcagacgttcagc \\
\hline \multirow[t]{2}{*}{ Pod15 } & $\operatorname{pod} 15 f$ & actttacatcccatgataggtctgg \\
\hline & pod15r & tgatatagcagaacacctgtgcagc \\
\hline \multirow[t]{2}{*}{ Pod15b } & pod15bf & aatcctggctaaatgcaagccttgg \\
\hline & pod15br & gccaggagaataagctactccatcc \\
\hline \multirow[t]{2}{*}{ Pod16 } & $\operatorname{pod} 16 f$ & ttcctttgttacaccttgggaggggt \\
\hline & pod16r & ctggagagggagcagcggcttcagg \\
\hline \multirow[t]{2}{*}{ Pod17 } & $\operatorname{pod} 17 f$ & taattgcccattcccttcgattccc \\
\hline & pod17r & tgataaccattgecttcattatgec \\
\hline \multirow[t]{2}{*}{ Pod20 } & pod20f & gagtgcttacaggctgtgaagatgt \\
\hline & pod20r & atgccgattcaaccaaaacatggcg \\
\hline \multirow[t]{2}{*}{ Pod 21} & $\operatorname{pod} 21 f$ & tctagagaccgagtccttgtaaggg \\
\hline & $\operatorname{pod} 21 r$ & gaaactcctctcccagagaacgacc \\
\hline \multirow[t]{2}{*}{ Pod 25} & $\operatorname{pod} 25 f$ & gtattatcaggcccagtgcttgtgg \\
\hline & $\operatorname{pod} 25 r$ & tggtggattatctatcatctgctcc \\
\hline \multirow[t]{2}{*}{ Pod31 } & pod31f & aacggctatttgcggactacagtag \\
\hline & pod31r & gcaggtcactaggaatatagaagcc \\
\hline \multirow[t]{2}{*}{ Pod33 } & pod33f & atctgatgggagagcattccacagg \\
\hline & pod33r & gtgcgccatattacacagcaactgg \\
\hline \multirow[t]{2}{*}{ Pod38 } & pod38f & agcgctgcaactttctctgcttccg \\
\hline & pod38r & gggcatgagtcaggagtagtcacgc \\
\hline \multirow[t]{2}{*}{ Pod43 } & pod43f & ccattacgtcaagtattgctaatgc \\
\hline & pod43r & catagagattcttatgcagaactgg \\
\hline \multirow[t]{2}{*}{ Pod55 } & pod55f & ggatctttataggagagtgcaggcc \\
\hline & pod55r & ttccagattgtgtttatcctggtgg \\
\hline \multirow[t]{2}{*}{ Pod69 } & pod69f & ttataagtgtgggagtagcgagctg \\
\hline & pod69r & ggagcattgaaaatatccaagatgg \\
\hline \multirow[t]{2}{*}{ Pod72 } & $\operatorname{pod} 72 f$ & gaagggagacggtgtgctattgtcg \\
\hline & $\operatorname{pod} 72 r$ & cctcctgctctctcttcctaacacg \\
\hline
\end{tabular}

detailed examination of variation in 49 individuals, including 13 P. vaucheri, 12 P. liolepis, 10 P. bocagei, nine $P$. muralis and five Corsican P. tiliguerta (see Additional file 1 for a complete list of the individuals used and their sampling localities). The first three species belong to the Iberian and North African clade, hence are closely related in comparison to the other two species, which are more distantly related (to the Iberian clade and to each other; see Figure 1 for a schematic representation of the phylogenetic relationships amongst these species based on [9]). Purification and sequencing of PCR products for this panel of samples (amplified using the same conditions described above) were carried out by Macrogen (http://dna.macrogen.com/eng/; Seoul, Korea).

Sequences were aligned using Sequencher v 4.1.4 [15]. The number of successful sequences obtained for each species was recorded. In sequences that were heterozygous for insertion/deletion (indel) polymorphisms, we used the method outlined by Flot et al. [16] to recover haplotypes. These were subsequently used in PHASE v. 2.1 [17] to assist haplotype reconstruction. PHASE was ran three times per dataset based on 100 burn-in and 100 post burn-in iterations and a thinning interval of 1 . We used the minimum value of 0.5 as the posterior probability threshold to accept a given reconstruction, as long as there was consistency among runs. Positions that were resolved inconsistently among runs were considered as "unphased" and were therefore replaced by a " $N$ " in the alignments. Phased alignments were imported into DNAsp [18] for polymorphism analyses. For each gene and species, we calculated nucleotide diversity $(\pi)$, number of segregating sites (S), number of haplotypes $(\mathrm{H})$ and haplotype diversity $(\mathrm{Hd})$, as well as Hudson and Kaplan's [19] Rm, indicating the minimum number of recombination events. We also computed the number of indel polymorphisms for each data set. To evaluate the possibility of a close genomic relationship between pairs of our markers, we further performed an exact test for genotypic disequilibrium per species using the program Genepop version 4.1.4 [20].

We obtained a total of 813 individual sequences among the 21 loci analysed in this study. Overall sequencing success results and polymorphism levels are shown in Table 2; detailed information concerning each species is reported in Additional file 2. Between 26 (Pod25) and 44 (Pod55, Pod69) individuals per locus were amplified and sequenced successfully. $P$. bocagei (rather than $P$. vaucheri, the original source of our library), showed the highest sequencing success rate on average $(86 \%)$, although this value is not significantly different from that in P. vaucheri (84\%) or P. liolepis (83\%) ( $\mathrm{p}>0.05$, based on a permutation test). In contrast, cross-amplification in $P$. muralis and $P$. tiliguerta was significantly less successful $(71 \%$ and $53 \%$ success rate 


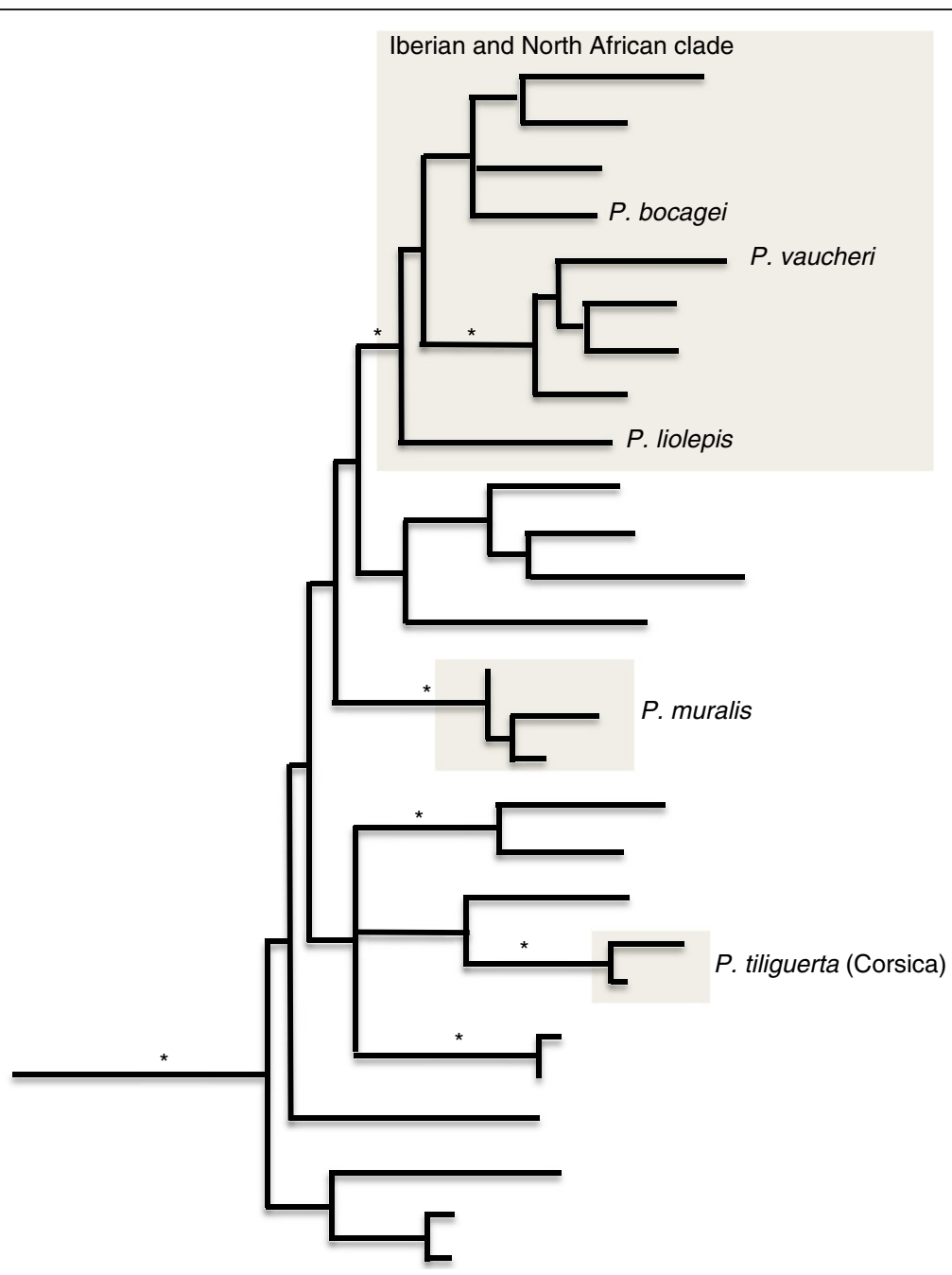

Figure 1 Schematic representation of the current hypothesis for evolutionary relationships within Podarcis (according to [9], based strictly on mitochondrial DNA), with an emphasis on the species included in this study. Please note that $P$. tiliguerta appears to be a complex of species; in this study only the Corsican form (highlighted in the figure) was included. Clades marked with an asterisk are statistically well-supported.

respectively) than in any of the Iberian and North African forms ( $\mathrm{p}<0.05$ for all comparisons involving $P$. muralis and $\mathrm{p}<0.01$ for all comparisons involving $P$. tiliguerta); these values account for the fact that one $(\operatorname{Pod} 12 b)$ and four (Pod6b, Pod13, Pod14, Pod38) loci failed to amplify or sequence in $P$. muralis and $P$. tiliguerta, respectively. This is in line with the current knowledge on these species evolutionary relationships, since $P$. bocagei, $P$. liolepis and $P$. vaucheri are all members of the Iberian and North African clade within the genus, whereas $P$. muralis and $P$. tiliguerta are more distantly related [9]. All loci except Pod43, Pod55 and Pod69 exhibited indel polymorphisms. With respect to polymorphism levels, for the complete five-species dataset, nucleotide diversity was on average 1.5\%, ranging from $0.035 \%$ in Pod43 to $3.5 \%$ in Pod 16. Diversity levels varied extensively among species (see Additional file 2); however, given the limited number of individuals included in this study and the fact that patterns of genetic variation are typically complex, our sampling schemes are not totally comparable across species; intraspecific polymorphism values should therefore be regarded as mere indications, and accordingly we have abstained from interpreting differences in polymorphism levels across species. There was no evidence for linkage disequilibrium between any pair of loci in any species (after Bonferroni correction).

For an additional characterization of these 21 loci, we performed a BLAST search of the sequenced clone sequence against the Anolis carolinensis genome (available in the NCBI website). Because Podarcis and Anolis are very distantly related, we used the "discontinuous megablast" algorithm to perform this search. Only 10 out of the 21 markers show a significant match to the Anolis genome (see Additional file 3). In many of these 
Table 2 Summary statistics for the loci developed in this study

\begin{tabular}{|c|c|c|c|c|c|c|c|c|c|c|c|c|}
\hline Locus & Species sequenced & $\begin{array}{l}\text { Success } \\
\text { rate (\%) }\end{array}$ & $\mathbf{N}$ & Sites (bp) & NetSites & $S$ & $\mathrm{H}$ & Hd & $\pi$ & $\mathrm{Rm}$ & Indels (size) & GenBank accession numbers \\
\hline Pod6b & $\mathrm{PB}, \mathrm{PL}, \mathrm{PV}, \mathrm{PM}$ & 76 & 74 & $481-491$ & 404 & 55 & 33 & 0.945 & 0.012 & 4 & $6(7 / 1 / 1 / 5 / 8 / 2)$ & KC680863 - KC680907 \\
\hline Pod7b & $\mathrm{PB}, \mathrm{PL}, \mathrm{PV}, \mathrm{PM}, \mathrm{PT}$ & 88 & 86 & $379-418$ & 312 & 42 & 26 & 0.918 & 0.018 & 2 & $5(1 / 7 / 20 / 19 / 6)$ & KC680908 - KC680951 \\
\hline Pod11 & PB, PL, PV, PM, PT & 86 & 84 & $432-437$ & 344 & 43 & 34 & 0.944 & 0.016 & 7 & $5(1 / \mathrm{M} / 5 / 1 / 1)$ & KC680952 - KC681005 \\
\hline Pod12b & PB, PL, PV, PT & 69 & 68 & $404-656$ & 288 & 65 & 32 & 0.933 & 0.025 & 4 & $9(6 / 7 / 1 / 1 / 1 / 245 / 3 / 3 / 1)$ & KC681006 - KC681046 \\
\hline Pod13 & $P B, P L, P V, P M$ & 71 & 70 & $367-381$ & 261 & 33 & 20 & 0.713 & 0.011 & 3 & $4(14 / 4 / 1 / 1)$ & KC681047 - KC681087 \\
\hline Pod14 & $P B, P L, P V, P M$ & 82 & 80 & $459-486$ & 363 & 33 & 27 & 0.918 & 0.016 & 4 & $6(10 / 22 / 21 / 1 / 3 / 9)$ & KC681088 - KC681136 \\
\hline Pod14b & $\mathrm{PB}, \mathrm{PL}, \mathrm{PV}, \mathrm{PM}, \mathrm{PT}$ & 84 & 82 & $486-508$ & 348 & 54 & 31 & 0.893 & 0.016 & 5 & 7 (3/M/4/M/28/1/4) & KC681137 - KC681183 \\
\hline Pod15 & PB, PL, PV, PM, PT & 82 & 80 & $498-540$ & 370 & 51 & 35 & 0.955 & 0.021 & 5 & $5(11 / 2 / 2 / 2 / 1)$ & KC681184 - KC681227 \\
\hline Pod15b & PB, PL, PV, PM, PT & 86 & 84 & $420-433$ & 399 & 41 & 35 & 0.939 & 0.009 & 5 & $5(\mathrm{M} / 13 / 2 / 2 / \mathrm{M})$ & KC681228 - KC681284 \\
\hline Pod16 & $\mathrm{PB}, \mathrm{PL}, \mathrm{PV}, \mathrm{PM}, \mathrm{PT}$ & 76 & 74 & $313-364$ & 213 & 46 & 38 & 0.972 & 0.035 & 6 & $11(18 / \mathrm{M} / 1 / 5 / 18 / 11 / 7 / 13 / 2 / 11 / 33)$ & KC681285 -- KC681332 \\
\hline Pod17 & PB, PL, PV, PM, PT & 88 & 86 & $380-405$ & 246 & 32 & 29 & 0.927 & 0.014 & 2 & $7(14 / 1 / 1 / 25 / M / 1 / 1)$ & KC681333 - KC681399 \\
\hline Pod20 & PB, PL, PV, PM, PT & 82 & 80 & $396-410$ & 305 & 34 & 27 & 0.913 & 0.012 & 1 & $4(1 / 1 / M / 13)$ & KC681400 - KC681448 \\
\hline Pod 21 & $P B, P L, P V, P M, P T$ & 86 & 84 & $303-316$ & 212 & 39 & 24 & 0.916 & 0.017 & 2 & $4(9 / 7 / 1 / 13)$ & KC681449 - KC681492 \\
\hline Pod 25 & $P B, P L, P V, P M, P T$ & 53 & 52 & $266-294$ & 233 & 29 & 21 & 0.937 & 0.020 & 2 & $4(1 / 18 / 8 / 2)$ & KC681493 - KC681522 \\
\hline Pod31 & $P B, P L, P V, P M, P T$ & 69 & 68 & 491-909 & 383 & 37 & 28 & 0.904 & 0.010 & 4 & $13(1 / 5 / 17 / 1 / 9 / 382 / 10 / 2 / 5 / 10 / 2 / 12 / 2)$ & KC681523 - KC681565 \\
\hline Pod33 & $P B, P L, P V, P M, P T$ & 86 & 84 & $325-340$ & 242 & 29 & 30 & 0.840 & 0.010 & 3 & $4(1 / 16 / 3 / M)$ & KC681566 - KC681614 \\
\hline Pod38 & $P B, P L, P V, P M$ & 80 & 78 & $536-539$ & 406 & 39 & 15 & 0.860 & 0.024 & 3 & $5(1 / 2 / 1 / 2 / 1)$ & KC681615 - KC681656 \\
\hline Pod43 & $\mathrm{PB}, \mathrm{PL}, \mathrm{PV}, \mathrm{PM}, \mathrm{PT}$ & 73 & 72 & 394 & 366 & 16 & 17 & 0.720 & 0.004 & 0 & 0 & KC681657 - KC681692 \\
\hline Pod55 & PB, PL, PV, PM, PT & 90 & 88 & 423 & 354 & 33 & 26 & 0.737 & 0.009 & 5 & 0 & KC681693 - KC681736 \\
\hline Pod69 & $\mathrm{PB}, \mathrm{PL}, \mathrm{PV}, \mathrm{PM}, \mathrm{PT}$ & 90 & 88 & 388 & 339 & 15 & 15 & 0.812 & 0.004 & 0 & 0 & KC681737 - KC681780 \\
\hline Pod72 & $\mathrm{PB}, \mathrm{PL}, \mathrm{PV}, \mathrm{PM}, \mathrm{PT}$ & 61 & 60 & $469-485$ & 358 & 52 & 20 & 0.884 & 0.023 & 8 & $6(1 / 5 / 11 / 1 / 7 / 14)$ & KC681781 - KC681810 \\
\hline
\end{tabular}

Species sequenced: PB Podarcis bocagei, PL P. liolepis, PV P. vaucheri, PM P. muralis, PT P. tiliguerta. N number of sequenced gene copies, Sites size range of sequences in the alignment, NetSites number of sites effectively used for polymorphism calculations (removing indels and Ns), $S$ number of segregating sites; $\pi$ nucleotide diversity, $H$ number of haplotypes, $H d$ haplotype diversity, $R m$ minimum number of recombination events [15], Indels number of insertion/deletion polymorphisms. The size of indels (with respect to each alignment) is reported in parentheses. $M$ means microsatellite-type indel. For the same information detailed by species, please see Additional file 2 . 
cases, functional annotation of the specific regions of the Anolis genome is still incomplete, which prevents an assessment of the putative genomic location of the markers. Only Pod31 and Pod33 appear to map within a protein-coding gene. Both loci comprise putatively exonic and intronic sequences: the first $\sim 170 \mathrm{bp}$ of the Pod31 and the last $86 \mathrm{bp}$ of the Pod33 alignments are probably exonic, whereas the remaining sequence of both markers is likely intronic. Pod20, Pod21 and Pod43 all map to intergenic regions. It is noteworthy that both Pod20 and Pod31 map to the Anolis chromosome 5. A more detailed look into these markers' genomic location shows that they are located about $\sim 8 \mathrm{Mb}$ apart in the genome, which could indicate that they may be under at least some physical linkage in Anolis. However, we have no evidence for any linkage disequilibrium between this (or any other) pair of loci in Podarcis, indicating that the markers may be on a different genomic location in this genus or that recombination rate between the two loci is high enough for the markers to behave as unlinked.

A potential problem in the development of anonymous genetic markers is the possibility of amplification of paralogs instead of single-copy loci. We cannot be completely sure that these markers all correspond to singlecopy markers and prospective users of these primers should be aware of this caveat. However, we did our best to minimize this problem by avoiding designing primers in repetitive elements (which are typically found in high copy numbers in the genome) and deliberately excluding loci presenting evidence for the amplification of paralogs. Furthermore, BLAST analyses against the Anolis carolinensis genome showed that most loci that did show significant similarity had a single match, which would not be expected if the markers were found in multiple copies. Furthermore, in the four loci that did have more than one significant match $(\operatorname{Pod} 7 b, \operatorname{Pod} 21$, Pod33, Pod55) the second most significant hit had a comparatively low total score, indicating that only a few base pairs - and not the whole locus - were found in common. This suggests either spurious matches or perhaps the presence of previously undescribed repetitive elements, but is not an indication of the amplification of paralogs. Finally, we have no evidence for the presence of more than two alleles per locus in any of the individuals sequenced in this study.

Given their high cross-amplification rate and of the existence of substantial intraspecific polymorphism, we predict these markers will be useful both in macroevolutionary (for e.g. species delimitation or phylogenetics) and microevolutionary (population genetics and phylogeography) frameworks. They may also be an important source from which to develop single nucleotide polymorphism (SNP) markers for the genus. Furthermore, albeit we were not able to perform a formal cross- amplification assay on other species, data from our laboratory suggest that a large proportion of the markers amplify well in other lacertid genera such as Timon or Scelarcis (C. Luís, unpublished data), and that at least Pod15b can be easily amplified in Archaeolacerta bedriagae (D. Salvi, pers. comm). The newly reported primer pairs are thus a valuable addition to the current genetics toolkit for Podarcis and probably for other lacertid species as well.

\section{Availability of supporting data}

The data sets supporting the results of this article are available in the GanBank repository, accession numbers KC680863-KC681810. Files containing all sampling localities, polymorphism and sequencing success values discriminated by species and results from a BLAST analysis against the Anolis carolinensis genome are provided as supplemental material.

\section{Additional files}

Additional file 1: Sampling locations for the 49 individuals included in the polymorphism assay.

Additional file 2: Summary statistics for the loci developed in this study, detailed by species.

Additional file 3: Results of BLAST analyses of the 21 loci developed in this study against the Anolis carolinensis genome.

\section{Competing interests}

The authors declare that they have no competing interests.

\section{Authors' contributions}

CPereira participated in the study conception, carried out most laboratory work, participated in sequence alignment, in data analyses and in the manuscript preparation. $\mathrm{AC}, \mathrm{CL}$ and $\mathrm{DC}$ participated in sequence alignment. SM participated in laboratory work. CPinho participated in the study conception, carried out laboratory work, participated in sequence alignment and in data analyses and wrote the initial draft of the paper. All authors read and approved the final manuscript.

\section{Acknowledgements}

This work was partially supported by FEDER through the COMPETE program and Portuguese national funds through the $F C T$ (Fundação para a Ciência e a Tecnologia) PTDC/BIA-BEC/102179/2008 research project and project

"Genomics and Evolutionary Biology" cofinanced by North Portugal Regional Operational Programme 2007/2013 (ON.2 - O Novo Norte), under the National Strategic Reference Framework (NSRF), through the European Regional Development Fund (ERDF). CPinho is supported by Programa Operacional Potencial Humano - Quadro de Referência Estratégico Nacional funds from the European Social Fund and the Portuguese Ministério da Educação e Ciência through a post-doctoral fellowship (FCT, SFRH/BPD/28869/2006).

\section{Author details}

${ }^{1} \mathrm{ClBIO} /$ UP, Centro de Investigação em Biodiversidade e Recursos Genéticos, Universidade do Porto, Campus Agrário de Vairão, Rua Padre Armando Quintas, 4485-661 Vairão, Portugal. Faculdade de Ciências da Universidade do Porto, Rua do Campo Alegre, s/n, 4169-007 Porto, Portugal.

Received: 22 February 2013 Accepted: 24 July 2013

Published: 27 July 2013 
1. Camargo A, Sinervo B, Sites Jr JW: Lizards as model organisms for linking phylogeographic and speciation studies. Mol Ecol 2010, 19:3250.

2. Pinho C, Harris DJ, Ferrand N: Genetic polymorphism of 11 allozyme loc in populations of wall lizards (Podarcis sp.) from the Iberian Peninsula and North Africa. Biochem Genet 2003, 41:343-359.

3. Pinho C, Sequeira F, Godinho R, Harris DJ, Ferrand N: Isolation and characterization of 9 microsatellite loci in Podarcis bocagei (Squamata: Lacertidae). Mol Ecol Notes 2004, 4:286-288.

4. Runemark A, Gabirot M, Bensch S, Svensson El, Martín J, Pafilis P, Valakos ED, Hansson B: Cross-species testing of 27 pre-existing microsatellites in Podarcis gaigeae and Podarcis hispanica (Squamata: Lacertidae). Mol Ecol Resour 2008, 8:1367-1370.

5. Pinho C, Harris DJ, Ferrand N: Non-equilibrium estimates of gene flow inferred from nuclear genealogies suggest that Iberian and North African wall lizards (Podarcis spp.) are an assemblage of incipient species. BMC Evol Biol 2008, 8:63.

6. Pinho C, Rocha S, Carvalho BM, Lopes S, Mourão S, Vallinoto M, Brunes TO, Haddad CFB, Gonçalves H, Sequeira F, Ferrand N: New primers for the amplification and sequencing of nuclear loci in a taxonomically wide set of reptiles and amphibians. Conserv Genet Resour 2010, 2(supp 1):181-185.

7. Poulakakis N, Lymberakis P, Antoniou A, Chalkia D, Zouros E, Mylonas M, Valakos E: Molecular phylogeny and biogeography of the wall-lizard Podarcis erhardii (Squamata: Lacertidae). Mol Phylogenet Evol 2003, 28:38-46.

8. Kaliontzopoulou A, Pinho C, Harris DJ, Carretero MA: When cryptic diversity blurs the picture: a cautionary tale from Iberian and North African Podarcis wall lizards. Biol J Linn Soc 2011, 103:779-800.

9. Harris DJ, Pinho C, Carretero MA, Corti C, Böhme W: Determination of genetic diversity within the insular lizar Podarcis tiliguerta using mtDNA sequence data, with a reassessment of the phylogeny of Podarcis. Amphibia-Reptilia 2005, 26:401-407.

10. Renoult JP, Geniez P, Bacquet P, Benoit L, Crochet PA: Morphology and nuclear markers reveal extensive mitochondrial introgressions in the Iberian Wall Lizard species complex. Mol Ecol 2009, 18:4298-4315.

11. Pinho C, Harris DJ, Ferrand N: Contrasting patterns of population structure and historical demography in three western Mediterranean lizard species inferred from mtDNA variation. Mol Ecol 2007, 16:1191-1205.

12. Tenzer I, Degli Ivanissevich S, Morgante M, Gessler C: Identification of microsatellite markers and their application to population genetics of Venturia inaequalis. Phytopathology 1999, 89(9):748-753.

13. Altschul SF, Gish W, Miller W, Myers EW, Lipman DJ: Basic local alignment search tool. J Mol Biol 1990, 215:403-410.

14. Smit AFA, Hubley R, Green P: RepeatMasker Open-3.0. 1996-2010. http://www.repeatmasker.org.

15. Sequencher ${ }^{\circledast}$ version 4.1.4 sequence analysis software. http://www.genecodes.com.

16. Flot J-F, Tillier A, Samadi S, Tillier S: Phase determination from direct sequencing of length-variable DNA regions. Mol Ecol Notes 2006 6:627-630.

17. Stephens M, Smith NJ, Donnelly P: A new statistical method for haplotype reconstruction from population data. Am J Hum Genet 2001, 68:978-989.

18. Librado P, Rozas J: DnaSP v5: a software for comprehensive analysis of DNA polymorphism data. Bioinformatics 2005, 25:1451-1452.

19. Hudson RR, Kaplan NL: Statistical properties of the number of recombination events in the history of a sample of DNA sequences. Genetics 1985, 111:147-164

20. Rousset F: Genepop'007: a complete re-implementation of the Genepop software for Windows and Linux. Mol Ecol Resour 2008, 8:103-106.

\section{Submit your next manuscript to BioMed Central and take full advantage of:}

- Convenient online submission

- Thorough peer review

- No space constraints or color figure charges

- Immediate publication on acceptance

- Inclusion in PubMed, CAS, Scopus and Google Scholar

- Research which is freely available for redistribution

Submit your manuscript at www.biomedcentral.com/submit
Ciomed Central 